\title{
Pelvic organ prolapse and uterine preservation: a cohort study (POP-UP study)
}

\author{
Daniel Gagyor ${ }^{1}$, Vladimir Kalis²,3 ${ }^{2}$, Martin Smazinka ${ }^{3}$, Zdenek Rusavy ${ }^{2,3}$, Radovan Pilka ${ }^{1}$
}

and Khaled M. Ismail ${ }^{2,4^{*}}$ (D)

\begin{abstract}
Background: Abdominal and laparoscopic sacro-colpopexy (LSC) is considered the standard surgical option for the management of a symptomatic apical pelvic organ prolapse (POP). Women who have their uterus, and for whom an LSC is indicated, can have a laparoscopic sacro-hysteropexy (LSH), a laparoscopic supra-cervical hysterectomy and laparoscopic sacro-cervicopexy (LSCH + LSC) or a total laparoscopic hysterectomy and laparoscopic sacro-colpopexy $(\mathrm{TLH}+\mathrm{LSC})$. The main aim of this study was to compare clinical and patient reported outcomes of uterine sparing versus concomitant hysterectomy LSC procedures.
\end{abstract}

Methods: A retrospective analysis of clinical, imaging and patient reported outcomes at baseline, 3 and 12 months after LSH versus either LSCH + LSC or TLH + LSC between January 2015 and January 2019 in a tertiary referral urogynecology center in Pilsen, the Czech Republic.

Results: In total, 294 women were included in this analysis ( $\mathrm{LSH} n=43, \mathrm{LSCH}+\mathrm{LSC} n=208$ and TLH $+\mathrm{LSC} n=43$ ). There were no differences in the incidence of perioperative injuries and complications. There were no statistically significant differences between the concomitant hysterectomy and the uterine sparing groups in any of the operative, clinical or patient reported outcomes except for a significantly lower anterior compartment failure rate $(p=0.017)$ and higher optimal mesh placement rate at 12 months in women who had concomitant hysterectomy procedures $(p=0.006)$.

Conclusion: LSH seems to be associated with higher incidence of anterior compartment failures and suboptimal mesh placement based on postoperative imaging techniques compared to LSC with concomitant hysterectomy.

Keywords: Laparoscopic, Sacrocolpopexy, Cervicopexy, Hysteropexy, LSC, LSCH + LSC, TLH + LSC, LSH, POP-Q, Mesh, PFDI, PGI-I, Compartment

\section{Background}

It is estimated that one in three women are affected by pelvic organ prolapse (POP) and one in 10 require a surgical procedure for its correction during their lifetime [1, 2]. POP is associated with numerous bothersome clinical symptoms including pelvic discomfort, vaginal bulge,

\footnotetext{
*Correspondence: khaled.ismail@lfp.cuni.cz

${ }^{4}$ Department of Gynecology and Obstetrics, Faculty of Medicine in Pilsen, Charles University, Pilsen, Czech Republic

Full list of author information is available at the end of the article

Daniel Gagyor and Vladimir Kalis are joint first authors.
}

urinary incontinence, urinary tract symptoms, fecal incontinence or sexual dysfunction. These often have a significant negative impact on their quality of life (QOL) or, even, serious life threatening consequences [3-8]. There is no significant correlation between the severity of clinical symptoms and the stage of POP, but there is a correlation between clinical symptoms and location of the underlying defect [9]. Anterior compartment prolapse tends to be associated with urgency symptoms requiring surgical intervention in the majority of cases 
[10], while posterior compartment prolapse is more likely to be associated with distal bowel dysfunction $[11,12]$.

Conservative management of apical prolapse is commonly used as first line treatment in general and the main option for women who have not completed their childbearing or those deemed to be at high operative risks. Nonetheless, surgical correction is an option that should always be discussed when counseling women about their treatment options. POP with a dominant apical defect can be treated using a number of surgical approaches and this choice can be one of the most challenging problems in urogynecology [13, 14]. However, high level evidence indicates that abdominal and laparoscopic sacro-colpopexy (LSC) result in better anatomical outcomes compared to sacrospinous ligament fixation and transvaginal mesh insertion [14]. Women who have their uterus and opt for a laparoscopic approach have several surgical options to consider; sacro-colpopexy, uterosacral ligament colpopexy [15], lateral ligament suspension or pecto-colpopexy [16]. Based on the currently available evidence, LSC is the most commonly used laparoscopic method and this could be in the form of laparoscopic sacro-hysteropexy (LSH), laparoscopic supra-cervical hysterectomy and laparoscopic sacro-cervicopexy (LSCH + LSC) or total laparoscopic hysterectomy and laparoscopic sacro-colpopexy (TLH + LSC).

The American College of Obstetricians and Gynecologists considers involving and supporting patients in the discussion about uterine preservation in elective surgery as obligatory [17]. Furthermore, there seems to be an increasing tendency for women to explore uterine preserving procedures for their POP surgical management rather than just accept a hysterectomy [18-20]. Therefore, increasing the availability of options, that do not necessitate a hysterectomy, gives women viable options to individualize their POP management plan. Nonetheless, one of the important determinants of women's choice about uterine preservation or concomitant hysterectomy is the outcome associated with either procedure [18-20]. There is evidence that the route of concomitant hysterectomy during LSC does not seem to be associated with the perioperative or postoperative outcomes [21, 22]. However, at present, there is heterogenous information about comparative anatomical and functional outcomes with no comprehensive analysis based on whether the uterus was spared or removed [23-26]. Furthermore, there is paucity of information on surgical outcomes including mesh placement on postoperative imaging.

\section{Methods}

The main aim of the study was to compare the clinical and patient reported outcomes of uterine sparing versus concomitant hysterectomy LSC procedures for a symptomatic apical POP. As a secondary aim we wanted to assess the peri- and postoperative complications associated with these procedures as an indicator of their safety profile.

This is a retrospective cohort study undertaken in a tertiary referral urogynecology center in Pilsen, the Czech Republic. All women referred with an intact uterus and a symptomatic apical POP and who were listed for one of the LSC procedures between January 2015 and January 2019 were included in our analysis. For the purpose of this study, we were interested in comparing women who had an LSH (uterine preservation) versus LSCH + LSC or TLH+LSC (concomitant hysterectomy). Local ethics committee approval was granted for the study. All patients included in this study provided written informed consent for the procedure and for the future use of their perioperative and follow-up data. The departmental medical database was used to gather data on patients' demographics, medical history, history of abdominal and/ or gynecological surgery, previous reconstructive POP surgery, obstetric history, urinary or bowel symptoms and POP-Q staging points $[27,28]$. We also collected data on hospital length of stay (LOS). Extended LOS was defined as hospitalization longer than the 75th percentile [29]. The impact of the woman's symptoms on her quality of life during the pre- and postoperative periods was assessed using the Pelvic Floor Distress Inventory (PFDI). This is a validated quality-of-life questionnaire consisting of a Urinary Distress Inventory (UDI), Pelvic Organ Prolapse Distress Inventory (POPDI) and a ColorectalAnal Distress Inventory (CRADI). UDI and POPDI have a score range of 0 (least impact) to 300 (greatest adverse impact) while CRADI has a range of 0 to 400 and an overall summary PFDI score ranging from 0 to 1000 [30]. Perioperative complications were categorized according to the Dindo-Clavien classification [31].

Surgical procedures were performed by one of four experienced urogynecological subspecialists. We used the same surgical technique, sutures and mesh materials for all LSC variants as previously published by our group $[32,33]$.

In the research unit, postoperative follow-up appointments are routinely arranged at 3 and 12 months for assessment of the impact of surgery on the woman's clinical symptoms, evaluation of any postoperative complications and clinical examination including a POP-Q measurement. In addition to the PFDI, their overall satisfaction with the surgical procedure is routinely evaluated by means of a 7-point Patient Global Impression of Improvement (PGI-I) scale ranging from "Very much worse" (PGI-I $=7)$ to "Very much better" (PGI-I=1) [34]. Any identified mesh related complications are reported using the current standardized international 
classification [35]. A 3D/4D transperineal ultrasound scans is also routinely performed at both follow-up appointments to assess the bladder neck and mesh positions. The ultrasound protocol has been previously published and is derived from the standardized assessment protocol suggested by Dietz et al. [32, 33, 36]. Optimal mesh placement is assessed based on a set of composite parameters including: distance of the lowest margin of the anterior mesh strand from the bladder neck $<20 \mathrm{~mm}$ [32, 33]; shape of the mesh; absence of folding; and a vertical mesh descent on Valsalva $\leq 20 \mathrm{~mm}$.

For the purpose of this study, anatomical apical compartment failure was defined as a postoperative POP-Q point $\mathrm{C} \geq-\mathrm{TVL} / 2 \mathrm{~cm}$ (apical descent lower than half of the vaginal length). Points $\mathrm{Ba}$ and $\mathrm{Bp} \geq-1 \mathrm{~cm}$ were considered failure in the anterior and posterior compartment respectively. Subjective success of the procedure was defined as a PGI-I<3 i.e. "Very Much" or "Much Better". Statistical analysis was performed using IBM SPSS Statistics software version 22 (Armonk, NY: IBM Corp.). A $\mathrm{p}<0.05$ was considered statistically significant.

In addition to the comparisons between uterine sparing versus concomitant hysterectomy LSC procedures, we undertook a sub-analysis comparing the three procedures (LSC, LSCH + LSC and TLH + LSC) to each other.

\section{Results}

A total of 421 LSC procedures were performed during the study period. Of these, 124 (29.5\%) procedures were performed on women who previously had a hysterectomy and hence excluded from this study. A further 3 patients $(0.7 \%)$ were not included because they had their procedure performed through a laparotomy. The remaining 294 (70.0\%) women who have had one of the LSC variants for apical POP management were all included in our analysis. These included $43(14.6 \%)$ women who had a uterine sparing procedure LSH and 251 (85.4\%) who had a concomitant hysterectomy, where $208(70.8 \%)$ had $\mathrm{LSCH}+\mathrm{LSC}$ and 43 women (14.6\%) had a TLH + LSC (Fig. 1).

Table 1 and Additional file 1 summarize participants' characteristics, preoperative POP-Q and PFDI scores grouped by whether the uterus was preserved or not and by type of procedure respectively. There were significant differences between the cohort of women who had LSH compared to LSCH + LSC/TLH + LSC with regards to BMI $\left(25.2 \mathrm{~kg} / \mathrm{m}^{2}\right.$ vs. $\left.26.6 \mathrm{~kg} / \mathrm{m}^{2}, p=0.006\right)$, age (49.0 years vs. 64.0 years, $p<0.0001)$ and comorbidities like cardiovascular disease $(20.9 \%$ vs. $55.8 \%$, $p<0.0001)$ and diabetes $(2.3 \%$ vs. $15.5 \%, p=0.02)$. There was also a significant difference in POP-Q staging based on point Ba between the 2 groups $(p<0.0001)$ (Table 1). There were significant differences in reported

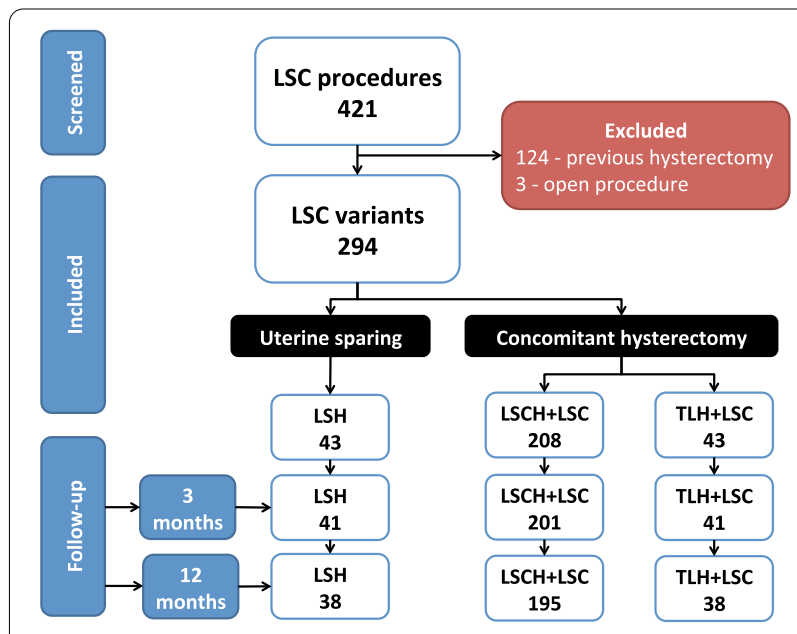

Fig. 1 Flowchart of study participants

urinary hesitancy $(30.2 \%$ vs. $49.0 \%, p=0.023)$ and constipation $(9.3 \%$ vs. $23.1 \%, p=0.04)$ between both cohorts. However, no significant differences were found in other pre-operative POP-Q parameters, reported urinary or anal incontinence, or preoperative PFDI score.

Operative characteristics and postoperative complications are presented in Table 2 and Additional file 2. Based on the Dindo-Clavien classification, there were no differences in the incidence of perioperative injuries and complications. However, operating time and blood loss were higher in the concomitant hysterectomy compared to the uterine sparing group (125 min vs. $120 \mathrm{~min}, p=0.052$ ).

Table 3 shows anatomical and functional outcomes at 3 and 12 months postoperative. When comparing outcomes in women who had a concomitant hysterectomy at the time of LSC compared to LSH, there were no statistically significant differences in any of the clinical or patient reported outcomes except for a significantly higher anterior compartment failure rate at 12 month follow-up as assessed by POP-Q in women who had a uterine sparing procedure $(21.1 \%$ vs. $7.7 \%, p=0.017)$ (Table 3, Additional file 3).

Moreover, concomitant hysterectomy procedures were likely to be associated with absent mesh folding on at $3(94.7 \%$ vs. $80.0 \%, \mathrm{p}=0.004)$ and 12 months $(93.8 \%$ vs. $82.1 \%, \mathrm{p}=0.021)$ and optimal composite mesh placement at 12 months $(81.7 \%$ vs. $67.6 \%, p=0.006)$ as assessed by ultrasonography (Table 4).

On subgroup analysis, the only significant difference was that the operative time was longer in the TLH + LSC subgroup compared to the LSH subgroups (140 min vs. $120 \mathrm{~min}, p=0.048)$. Furthermore, blood loss was 
Table 1 Demographic details of study cohorts

\begin{tabular}{|c|c|c|c|c|c|}
\hline Variable & & $\begin{array}{l}\text { Total population } \\
\mathrm{N}=294\end{array}$ & $\begin{array}{l}\text { Uterine sparing } \\
\text { (LSH) } \\
\mathrm{N}=43\end{array}$ & $\begin{array}{l}\text { Concomitant } \\
\text { Hysterectomy } \\
\text { (LSCH+ LSC \& } \\
\text { TLH+ LSC) } \\
\mathrm{N}=251\end{array}$ & $p$ \\
\hline BMI [Median (range)] & & $26.4(17.7-37.2)$ & $25.2(17.7-31.6)$ & $26.6(19.2-37.2)$ & $0.006^{\mathrm{a}}$ \\
\hline Age [Median (range)] & & $63.0(28-84)$ & $49.0(28-70)$ & $64.0(37-84)$ & $<0.0001^{\mathrm{a}}$ \\
\hline Parity [Median (range)] & & $2.0(0-9)$ & $2.0(1-5)$ & $2.0(0-9)$ & $0.063^{\mathrm{a}}$ \\
\hline Cardiovascular disease [N (\%)] & & $149(50.7 \%)$ & $9(20.9 \%)$ & $140(55.8 \%)$ & $<0.0001^{\mathrm{b}}$ \\
\hline Diabetes mellitus [N (\%)] & & $40(13.6 \%)$ & $1(2.3 \%)$ & $39(15.5 \%)$ & $0.020^{b}$ \\
\hline Previous DVT or pulmonary embolism [N (\%)] & & $39(13.3 \%)$ & $3(7.0 \%)$ & $36(14.3 \%)$ & $0.188^{b}$ \\
\hline Asthma [N (\%)] & & $22(7.5 \%)$ & $1(2.3 \%)$ & $21(8.4 \%)$ & $0.219^{c}$ \\
\hline Previous abdominal surgical history [N (\%)] & & $137(46.6 \%)$ & $17(39.5 \%)$ & $120(47.8 \%)$ & $0.315^{b}$ \\
\hline Previous gynecologic surgery [N (\%)] & & $90(30.6 \%)$ & $15(34.9 \%)$ & $85(33.9 \%)$ & $0.896^{\mathrm{b}}$ \\
\hline Previous POP surgery [N (\%)] & & $6(2.0 \%)$ & $2(4.7 \%)$ & $4(1.6 \%)$ & $0.214^{c}$ \\
\hline Point $C$ & POP Q stage I & $19(6.5 \%)$ & $5(11.6 \%)$ & $14(5.6 \%)$ & $0.073^{b}$ \\
\hline & POP Q stage ॥ & 159 (54.1\%) & $24(55.8 \%)$ & 135 (53.8\%) & \\
\hline & POP Q stage III & 78 (26.5\%) & $11(25.6 \%)$ & 67 (26.7\%) & \\
\hline & POP Q stage IV & 38 (12.9\%) & $3(7.0 \%)$ & 55 (21.9\%) & \\
\hline Point Ba & POP Q stage I & $3(1.0 \%)$ & $1(2.3 \%)$ & $2(0.8 \%)$ & $<0.0001^{b}$ \\
\hline & POP Q stage II & 65 (22.1\%) & $28(65.1 \%)$ & 37 (14.7\%) & \\
\hline & POP Q stage III & 165 (56.1\%) & $11(25.6 \%)$ & $154(61.4 \%)$ & \\
\hline & POP Q stage IV & $51(17.4 \%)$ & $3(7.0 \%)$ & 48 (19.1\%) & \\
\hline Point Bp & POP Q stage I & $96(32.7 \%)$ & 13 (30.2\%) & 83 (33.1\%) & $0.634^{b}$ \\
\hline & POP Q stage ॥ & 132 (44.9\%) & $22(51.2 \%)$ & $110(43.8 \%)$ & \\
\hline & POP Q stage III & $46(15.6 \%)$ & $7(16.3 \%)$ & 39 (15.5\%) & \\
\hline & POP Q stage IV & $20(6.8 \%)$ & $1(2.3 \%)$ & $19(7.6 \%)$ & \\
\hline Stress urinary incontinence [N (\%)] & & $87(29.6 \%)$ & $11(25.6 \%)$ & $76(60.3 \%)$ & $0.533^{b}$ \\
\hline Urge urinary incontinence [N (\%)] & & $66(22.4 \%)$ & $8(18.6 \%)$ & $58(23.1 \%)$ & $0.513^{b}$ \\
\hline Hesitancy: a delay in initiating micturition [N (\%)] & & $136(46.3 \%)$ & $13(30.2 \%)$ & $123(49.0 \%)$ & $0.023^{b}$ \\
\hline Urinary retention [N (\%)] & & $126(42.9 \%)$ & $21(48.8 \%)$ & $115(45.8 \%)$ & $0.714^{b}$ \\
\hline Constipation [N (\%)] & & $62(21.1 \%)$ & $4(9.3 \%)$ & $58(23.1 \%)$ & $0.040^{b}$ \\
\hline Anal incontinence [N (\%)] & & 102/266 (38.3\%) & 16/41 (39.0\%) & $86 / 225(38.2 \%)$ & $0.923^{b}$ \\
\hline Pre-op UDI [median (range)] & & $51.2(0-189)$ & $52.6(5.8-164)$ & $51.2(0-189)$ & $0.481^{\mathrm{a}}$ \\
\hline Pre-op POPDI [median (range)] & & $68.5(0-282)$ & $58.9(10.7-152)$ & $69.6(0-282)$ & $0.204^{\mathrm{a}}$ \\
\hline Pre-op CRADI [median (range)] & & $35.1(0-216)$ & $34.2(0-164)$ & $36.4(0-216)$ & $0.963^{\mathrm{a}}$ \\
\hline Pre-op PFDI [median (range)] & & $171.7(0-600)$ & $148.0(16.5-442)$ & $1712.4(0-600)$ & $0.524^{\mathrm{a}}$ \\
\hline
\end{tabular}

a Mann-Whitney U test; ${ }^{\mathrm{b}}$ Chi-square Test; ${ }^{\mathrm{c}}$ Fisher's exact Test

BMI: body mass index, DVT: deep venous thromboembolism

significantly higher when comparing TLH + LSC to LSH $(250 \mathrm{ml}$ vs. $150 \mathrm{ml}, p=0.001)$ and $\mathrm{TLH}+\mathrm{LSC}$ to $\mathrm{LSCH}+\mathrm{LSC}(250 \mathrm{ml}$ vs. $150 \mathrm{ml}, p<0.0001)$.

\section{Discussion}

\section{Summary of findings}

This is among the first studies comparing outcomes of the different variants of LSC with a particular focus on comparing these outcomes based on whether the uterus was spared or concomitantly removed. Of the total number of women who had an LSC procedure during the study period, $70 \%$ of women who presented with a significant apical POP requiring surgery had their uterus in situ. The majority of these women had a concomitant hysterectomy at the time of LSC. Our study demonstrated that LSC procedures with a concomitant total hysterectomy were associated with statistically significantly longer operating time and intra-operative blood loss. However, the median differences between groups were only $5 \mathrm{~min}$ and $50 \mathrm{ml}$ respectively. In contrast, uterine sparing LSCs were associated with a significantly higher likelihood of a suboptimally placed mesh at 3 and 12 months 
Table 2 Peri-operative characteristics amongst study cohorts

\begin{tabular}{|c|c|c|c|c|}
\hline Variable & $\begin{array}{l}\text { Total population } \\
\mathrm{N}=294\end{array}$ & $\begin{array}{l}\text { Uterine sparing } \\
\text { (LSH) } \\
\mathrm{N}=43\end{array}$ & $\begin{array}{l}\text { Concomitant } \\
\text { Hysterectomy } \\
\text { (LSCH + LSC \& } \\
\text { TLH+ LSC) } \\
\mathrm{N}=251\end{array}$ & $p$ \\
\hline Operating time [min] [Median (range)] & $120.5(60-240)$ & $120.0(70-225)$ & $125.0(60-240)$ & $0.052^{\mathrm{a}}$ \\
\hline Operating time more than $3 \mathrm{~h}[\mathrm{~N}(\%)]$ & $16(5.4 \%)$ & $2(4.7 \%)$ & $14(5.6 \%)$ & $1.000^{\mathrm{b}}$ \\
\hline Blood loss [ml] [Median (range)] & $150(50-1400)$ & $150(50-1400)$ & $200(50-800)$ & $0.259^{\mathrm{a}}$ \\
\hline Estimated blood loss more than $300 \mathrm{ml}$ [N (\%)] & $14(4.7 \%)$ & $2(4.7 \%)$ & $12(4.8 \%)$ & $1.000^{\mathrm{b}}$ \\
\hline Perioperative blood transfusion & $2(0.7 \%)$ & $1(2.3 \%)$ & $1(0.4 \%)$ & $0.286^{\mathrm{b}}$ \\
\hline Bladder injury [N (\%)] & $10(3.4 \%)$ & $2(4.7 \%)$ & $8(3.2 \%)$ & $0.657^{\mathrm{b}}$ \\
\hline Rectal injury [N (\%)] & $0(0.0 \%)$ & $0(0.0 \%)$ & $0(0.0 \%)$ & - \\
\hline Vaginal injury [N (\%)] & $2(0.7 \%)$ & $0(0.0 \%)$ & $2(0.8 \%)$ & $1.000^{\mathrm{b}}$ \\
\hline Early postoperative complications Dindo-Clavien grade 0 [N (\%)] & $281(95.6 \%)$ & $41(95.3 \%)$ & $240(95.6 \%)$ & $0.566^{\mathrm{b}}$ \\
\hline Early postoperative complications Dindo-Clavien grade I [N (\%)] & $6(2.0 \%)$ & $1(2.3 \%)$ & $5(2.0 \%)$ & \\
\hline Early postoperative complications Dindo-Clavien grade II [N (\%)] & $3(1.0 \%)$ & $1(2.3 \%)$ & $2(0.8 \%)$ & \\
\hline Early postoperative complications Dindo-Clavien grade III [N (\%)] & $4(1.4 \%)$ & $0(0.0 \%)$ & $4(1.6 \%)$ & \\
\hline Prolonged hospitalization [N (\%)] & $6(2.0 \%)$ & $2(4.7 \%)$ & $4(1.6 \%)$ & $0.234^{b}$ \\
\hline
\end{tabular}

a Mann-Whitney U test; ${ }^{\mathrm{b}}$ Fisher's Exact Test

postoperative and anterior compartment failures at 12 months. Nevertheless, other anatomical and patient reported outcomes were comparable in both groups. On head to head comparison of the different LSC variants there was no significant difference in anterior compartment failure rates. However, this observation should be interpreted with caution due to the small samples in some of the subgroups.

\section{Results in relation to what is known}

Other groups have reported higher incidence of anatomical failures in association with LSH [23, 24]. Saliba et al. compared outcomes of $64 \mathrm{LSCH}+\mathrm{LSC}$ versus $12 \mathrm{LSH}$ procedures and the anatomical failure, defined as POP stage $\geq 2$, was significantly higher in the LSH groups in both any and apical compartments (33.3\% vs. $6.2 \%$ and $16.7 \%$ vs. $0 \%$ respectively), however, the study authors did not provide the actual length of follow-up [24]. Similarly, Gracia and colleagues reported significantly higher apical compartment failures, defined as $C$ stage $\geq 2$, when comparing 12 months outcomes after 15 LSH compared to 30 LSCH + LSC (53.2\% vs. 10.0\%). Anterior compartment recurrence (Ba stage $\geq 2$ ) was also more common in their LSH cohort (72.4\% vs. 33.3\%) [23]. The reported incidence of anterior compartment failures concur with our findings of $21.1 \%$ vs. $8.8 \%$ in our LSH and LSCH + LSC subgroups respectively. Nevertheless, our low incidence of apical compartment recurrences both in the main and subgroup analyses are in stark contrast to the rates reported in these studies.
When comparing LSH and TLH + LSC, we did not have any apical compartment recurrences at 12 months compared to Pan et al. who reported $13.9 \%$ and $5.9 \%$ recurrence rates for the equivalent procedures in a cohort of 65 and 34 women who had LSH and TLH + LSC respectively, albeit, after an average follow-up of 34 months. Moreover, their anterior compartment failure rates were $13.9 \%$ versus $11.8 \%$ compared to $21.1 \%$ versus $5.2 \%$ in our study, while their posterior compartment recurrence incidences were $4.6 \%$ versus $5.9 \%$ and it was $0 \%$ and $15.8 \%$ in our LSH and TLH + LSC groups respectively [25]. The identified posterior compartment failure rate in our TLH + LSC was also higher than that reported by Illiano and associates (15.8\% compared to $2.4 \%$ ) [26]. Due to the nature of our study we were not able to explore the reasons behind the aforementioned differences in recurrence rates between our study and previous reports, which could be related to the operative technique, patient selection or duration of follow-up. Another reason for discrepancy in reported outcome rates between various studies is the POP-Q cut-off used to determine failure. Indeed, if we use the $\mathrm{Ba}>0$ cut-off for cystocele recurrence adopted in other studies [32, 37], our anterior compartment failure rates would have dropped to zero.

We identified a significantly higher likelihood of suboptimal mesh placement in our LSH group, which probably is an indicator of the relative technical difficulty of inserting the mesh in LSH compared to other variants of LSC. It would be of interest to assess if there is any association between mesh placement and clinical outcomes. However, we did not undertake such analysis because we 
Table 3 Post-operative follow-up at 3 months and at 12 months

\begin{tabular}{|c|c|c|c|c|c|c|c|c|}
\hline & \multicolumn{4}{|c|}{$\begin{array}{l}3 \text { month follow-up } \\
N=283\end{array}$} & \multicolumn{4}{|c|}{$\begin{array}{l}12 \text { month follow-up } \\
N=271\end{array}$} \\
\hline & $\begin{array}{l}\text { Total } \\
\mathrm{N}=\mathbf{2 8 3}\end{array}$ & $\begin{array}{l}\text { Uterine sparing } \\
\text { (LSH) } \\
\mathrm{N}=41\end{array}$ & $\begin{array}{l}\text { Concomitant } \\
\text { hysterectomy } \\
\text { (LSCH+LSC \& } \\
\text { TLH+ LSC) } \\
\mathrm{N}=242\end{array}$ & $p$ & $\begin{array}{l}\text { Total } \\
\mathrm{N}=271\end{array}$ & $\begin{array}{l}\text { Uterine sparing } \\
\text { (LSH) } \\
\mathrm{N}=38\end{array}$ & $\begin{array}{l}\text { Concomitant } \\
\text { hysterectomy } \\
\text { (LSCH+ LSC \& } \\
\text { TLH+LSC) } \\
\mathrm{N}=233\end{array}$ & $p$ \\
\hline $\begin{array}{l}\text { Postoperative } \\
\text { mesh complica- } \\
\text { tions [N/N] (\%) }\end{array}$ & $2 / 283(0.7 \%)$ & $0 / 41(0.0 \%)$ & $2 / 242(0.8 \%)$ & $1.000^{\mathrm{b}}$ & $4 / 271(1.5 \%)$ & $1 / 38(2.6 \%)$ & $3 / 233(1.3 \%)$ & $0.456^{b}$ \\
\hline $\begin{array}{l}\text { Failure in apical } \\
\text { compartment } \\
\text { Point } C \geq-T V L / 2 \\
{[N / N](\%)}\end{array}$ & 0/283 (0.0\%) & 0/41 (0.0\%) & $0 / 242(0 \%)$ & - & $0 / 271(0.0 \%)$ & 0/38 (0.0\%) & 0/233 (0\%) & - \\
\hline $\begin{array}{l}\text { Failure in anterior } \\
\text { compartment } \\
\text { Point } \mathrm{Ba} \geq 1[\mathrm{~N} / \mathrm{N}] \\
(\%)\end{array}$ & $12 / 283(4.2 \%)$ & $4 / 41(9.8 \%)$ & $8 / 242(3.3 \%)$ & $0.079^{b}$ & $26 / 271(9.6 \%)$ & $8 / 38(21.1 \%)$ & 18/233 (7.7\%) & $0.017^{b}$ \\
\hline $\begin{array}{l}\text { Failure in poste- } \\
\text { rior compart- } \\
\text { ment } \\
\text { Point } \mathrm{Bp} \geq-1 \\
{[\mathrm{~N} / \mathrm{N}](\%)}\end{array}$ & $14 / 283(4.9 \%)$ & $0 / 41(0.0 \%)$ & $14 / 242(5.8 \%)$ & $0.114^{b}$ & $15 / 271(5.5 \%)$ & $0 / 38(0.0 \%)$ & $15 / 233(6.4 \%)$ & $0.140^{b}$ \\
\hline $\begin{array}{l}\text { PGI-I 1, } 2[\mathrm{~N} / \mathrm{N}] \\
(\%)\end{array}$ & 243/283 (85.9\%) & $35 / 41(85.4 \%)$ & 208/242 (86.0\%) & $0.607^{b}$ & 255/271 (94.1\%) & $33 / 38(86.8 \%)$ & $222 / 233(95.3 \%)$ & $0.055^{\mathrm{b}}$ \\
\hline PGI-I 3 [N/N] (\%) & 28/283 (9.9\%) & 4/41 (9.8\%) & $24 / 242$ (9.9\%) & & $11 / 271(4.0 \%)$ & 3/38 (7.9\%) & 8/233 (3.4\%) & \\
\hline PGI-I 4 [N/N] (\%) & $8 / 283(2.8 \%)$ & $1 / 41(2.4 \%)$ & $7 / 242(2.9 \%)$ & & $4 / 271(1.5 \%)$ & $2 / 38(5.3 \%)$ & 2/233 (0.9\%) & \\
\hline PGI-I 5 [N/N] (\%) & $2 / 283(0.7 \%)$ & $1 / 41(2.4 \%)$ & $1 / 242(0.4 \%)$ & & $1 / 271(0.4 \%)$ & 0/38 (0.0\%) & $1 / 233(0.4 \%)$ & \\
\hline PGI-I 6 [N/N] (\%) & $2 / 283(0.7 \%)$ & 0/41 (0.0\%) & $2 / 242(0.8 \%)$ & & 0/271 (0.0\%) & 0/38 (0.0\%) & 0/233 (0\%) & \\
\hline PGI-I 7 [N/N] (\%) & 0/286 (0.0\%) & 0/41 (0.0\%) & 0/242 (0\%) & & 0/271 (0.0\%) & 0/38 (0.0\%) & 0/233 (0\%) & \\
\hline $\begin{array}{l}\Delta \text { UDI pre-op } \\
\text { - post-op } \\
\text { [median } \\
\text { (range)] }\end{array}$ & $\begin{array}{l}20.1(-159 \text { to } \\
153)\end{array}$ & $\begin{array}{l}17.9(-54.9 \text { to } \\
131)\end{array}$ & $\begin{array}{l}20.1(-159 \text { to } \\
153)\end{array}$ & $0.988^{\mathrm{a}}$ & $\begin{array}{l}25.0(-112 \text { to } \\
160)\end{array}$ & $\begin{array}{l}17.6(-99 \text { to } \\
160)\end{array}$ & $\begin{array}{l}33.7(-112 \text { to } \\
150)\end{array}$ & $0.585^{\mathrm{a}}$ \\
\hline $\begin{array}{l}\triangle \text { POPDI pre- } \\
\text { op - post-op } \\
\text { [median } \\
\text { (range)] }\end{array}$ & $\begin{array}{l}40.5(-112 \text { to } \\
256)\end{array}$ & $\begin{array}{l}35.7(-56 \text { to } \\
127)\end{array}$ & $\begin{array}{l}41.1(-112 \text { to } \\
256)\end{array}$ & $0.559^{\mathrm{a}}$ & $\begin{array}{l}39.3(-74 \text { to } \\
253)\end{array}$ & $\begin{array}{l}30.4(-43 \text { to } \\
135)\end{array}$ & $\begin{array}{l}48.2(-189 \text { to } \\
253)\end{array}$ & $0.502^{\mathrm{a}}$ \\
\hline $\begin{array}{l}\triangle \text { CRADI pre- } \\
\text { op - post-op } \\
\text { [median } \\
\text { (range)] }\end{array}$ & $\begin{array}{l}7.7(-189 \text { to } \\
199)\end{array}$ & $\begin{array}{l}10.0(-41 \text { to } \\
129)\end{array}$ & 7.1 ( -189 to 199$)$ & $0.338^{\mathrm{a}}$ & $3.6(-92$ to 170$)$ & $\begin{array}{l}10.7(-38 \text { to } \\
112)\end{array}$ & 7.1 (- 118 to 170$)$ & $0.187^{\mathrm{a}}$ \\
\hline $\begin{array}{l}\triangle \text { PFDI pre- } \\
\text { op - post-op } \\
\text { [median } \\
\text { (range)] }\end{array}$ & $\begin{array}{l}46.1(-342 \text { to } \\
450)\end{array}$ & $\begin{array}{l}50.7(-206 \text { to } \\
373)\end{array}$ & $\begin{array}{l}59.5(-343 \text { to } \\
450)\end{array}$ & $0.889^{\mathrm{a}}$ & $\begin{array}{l}70.4(-182 \text { to } \\
460)\end{array}$ & $\begin{array}{l}66.9(-123 \text { to } \\
281)\end{array}$ & $\begin{array}{l}82.5(-338 \text { to } \\
460)\end{array}$ & $0.960^{\mathrm{a}}$ \\
\hline
\end{tabular}

a Mann-Whitney U test; ${ }^{b}$ Fisher's Exact Test; UUI: Urge urinary incontinence; SUl: Stress urinary incontinence

believe our study is underpowered to test such hypothesis. The incidence of postoperative mesh-related complications in our study falls within the range of $1.0-2.6 \%$. However, the incidence of mesh erosions were similar in our subgroup analyses unlike the differences reported by other authors [38-40]. It is the technical challenge to achieve proper placement of the anterior mesh in LSH and be able to create a "de novo vaginal apex" that is considered to be a plausible reason for the higher anterior compartment failure in association with LSH and is the driver behind the suggestion of alternative modifications to the standard technique [41]. The process of refining the current LSH technique is crucially important since the number of women opting for uterine sparing surgery significantly falls if this technique is associated with inferior anatomical outcome $[18,19]$. 
Table 4 Mesh placement on transperineal scanning at 3 months and at 12 months

\begin{tabular}{|c|c|c|c|c|c|c|c|c|}
\hline & \multicolumn{4}{|c|}{$\begin{array}{l}3 \text { month follow-up } \\
N=283\end{array}$} & \multicolumn{4}{|c|}{$\begin{array}{l}12 \text { month follow-up } \\
N=271\end{array}$} \\
\hline & $\begin{array}{l}\text { Total } \\
\mathrm{N}=283\end{array}$ & $\begin{array}{l}\text { Uterine sparing } \\
\text { (LSH) } \\
\mathrm{N}=41\end{array}$ & $\begin{array}{l}\text { Concomitant } \\
\text { hysterectomy } \\
\text { (LSCH + LSC \& } \\
\text { TLH+ LSC) } \\
\mathrm{N}=242\end{array}$ & $p$ & $\begin{array}{l}\text { Total } \\
\mathrm{N}=271\end{array}$ & $\begin{array}{l}\text { Uterine sparing } \\
\text { (LSH) } \\
\mathrm{N}=38\end{array}$ & $\begin{array}{l}\text { Concomitant } \\
\text { hysterectomy } \\
\text { (LSCH + LSC \& } \\
\text { TLH+LSC) } \\
\mathrm{N}=233\end{array}$ & $p$ \\
\hline $\begin{array}{l}\text { Regular shape of the } \\
\text { mesh upon visualiza- } \\
\text { tion of the whole } \\
\text { mesh [N/N](\%) }\end{array}$ & $244 / 266(91.7 \%)$ & $35 / 40(87.5 \%)$ & $209 / 226(92.5 \%)$ & $0.345^{b}$ & $238 / 265$ (89.8\%) & $32 / 39(82.1 \%)$ & $206 / 226(91.2 \%)$ & $0.090^{b}$ \\
\hline $\begin{array}{l}\text { No folding of the mesh } \\
{[N / N](\%)}\end{array}$ & $248 / 268(92.5 \%)$ & $32 / 40$ (80.0\%) & $216 / 228(94.7 \%)$ & $0.004^{b}$ & $245 / 266(92.1 \%)$ & $32 / 39(82.1 \%)$ & $213 / 227(93.8 \%)$ & $0.021^{b}$ \\
\hline $\begin{array}{l}\text { No mesh descent on } \\
\text { Valsalva 196/226 } \\
\text { (86.7\%) [N/N](\%) }\end{array}$ & 266/268 (99.3\%) & $39 / 40$ (97.5\%) & 227/228 (99.6\%) & $0.277^{b}$ & $252 / 254(99.2 \%)$ & $36 / 37$ (97.3\%) & $216 / 217$ (99.5\%) & $0.271^{b}$ \\
\hline $\begin{array}{l}\text { Overall evaluation: all } \\
\text { criteria for a properly } \\
\text { placed mesh fulfilled } \\
{[\mathrm{N} / \mathrm{N}](\%)}\end{array}$ & $227 / 266(85.3 \%)$ & $31 / 40$ (77.5\%) & 196/226 (86.7\%) & $0.146^{b}$ & $214 / 254$ (84.3\%) & 25/37 (67.6\%) & 189/217 (81.7\%) & $0.006^{b}$ \\
\hline
\end{tabular}

a Mann-Whitney U test; ${ }^{\mathrm{b}}$ Fisher's Exact Test

\section{Strengths and limitations}

We appreciate that there are some limitations to our work. First, the retrospective nature of the study has an inherent risk of introducing selection and recall bias into our data. Due to the rigor in our hospital database and the high level of specialism required for the surgical procedures being assessed, it is extremely unlikely we would have missed any procedures or data that was collected. However, the issue of selection bias is more challenging to tackle except within a context of a randomized trial. Indeed, our 2 groups of interest had significant differences in their demographics and associated comorbidities. Second, although we report 12-month follow-up data, in POP surgery, this is considered relatively short. We recognize that the longer the follow-up the higher attrition rate, hence, the current study will form the basis for our LSC database that will enable us to increase our sample size and assess longer term outcomes. Although our sample size in the uterine sparing cohort was relatively small, a post hoc power calculation showed that the power of our study to identify the difference in anterior compartment failure rates between our main cohorts at a significance level of 0.05 was $70 \%$ (Additional file 4). Finally, it could be perceived that a report from a single center might limit the external validity of the study. However, the involvement of several independent trained surgeons, in a center accredited by the European Board \& College of Obstetrics and Gynaecology (EBCOG) for training and the use of standardized operative technique and validated outcome measures make our findings generalizable. In contrast, the reporting on LSC variants based on whether the uterus was removed or spared using a comprehensive set of core outcomes and the novelty of the postoperative imaging information are major strengths to our study.

\section{Conclusion}

Many women referred with a symptomatic apical POP have their uterus in situ. LSH was associated with higher incidence of anterior compartment failures and suboptimal mesh placement compared to LSC with concomitant hysterectomy. LSCH + LSC appears to have the best balance between limiting operative time and blood loss against recurrence rates at 12 months. The availability of longer-term outcomes for the different LSC variants and the assessment of proposed new modifications to overcome challenges to mesh placement in LSH are essential to give women realistic prospects of making an equitable informed choice.

\section{Supplementary Information}

The online version contains supplementary material available at https://doi. org/10.1186/s12905-021-01208-5.

Additional file 1. Demographic data amongst women undergoing $L S H$, $\mathrm{LSCH}+\mathrm{LSC}$ and TLH+LSC

Additional file 2. Peri-Operative characteristics amongst women undergoing $L S H, L S C H+L S C$ and $T L H+L S C$

Additional file 3. Post-operative follow-up at 3 months and at 12 months. Additional file 4. Post hoc power calculation 


\begin{abstract}
Abbreviations
CRADI: Colorectal-Anal Distress Inventory; LSC: Laparoscopic sacro-colpopexy; LSCH + LSC: Laparoscopic supra-cervical hysterectomy and Laparoscopic sacro-cervicopexy; LSH: Laparoscopic sacro-hysteropexy; PGI-I: Patient Global Impression of Improvement; POP: Pelvic organ prolapse; POPDI: Pelvic Organ Prolapse Distress Inventory; POP-Q: Pelvic organ prolapse quantitation system; PFDI: Pelvic Floor Distress Inventory; TLH + LSC: Total laparoscopic hysterectomy and laparoscopic sacro-colpopexy; QOL: Quality of life; UDI: Urinary Distress Inventory.
\end{abstract}

\section{Acknowledgements}

some of the procedures analyzed in this study contributed data to other studies that were designed to answer different research questions [32, 33].

\section{Authors' contributions}

DG: Literature search, Data collection, Manuscript writing. VK: Project development, Literature search, Data collection, Manuscript writing. MS: Data collection. ZR: Data collection, Manuscript editing and revision. RP: Project development, Manuscript editing and revision. KMI: Project development, Literature search, Manuscript editing and revision. All authors read and approved the final manuscript.

\section{Funding}

The study was funded by National Sustainability Program I (NPU I) Nr. LO1503 and Charles University Research Fund (Progress Q39). The funders did not have a role in the collection, analysis and interpretation of data and in the writing of the manuscript. Kl is part-funded by project No. CZ.02.1.01/0.0/0.0/16_019/ 0000787 "Fighting INfectious Diseases", awarded by the Ministry of Education, Youth and Sports of the Czech Republic, financed from The European Regional Development Fund. Funders were not involved in the design, analysis or the reporting of this work.

\section{Availability of data and materials}

The datasets used and/or analysed during the current study are available from the corresponding author on reasonable request.

\section{Consent for publication}

Not applicable.

\section{Ethics approval and consent to participate}

Local ethics committee approval was granted for the study by Lokální etická komise (Local ethical committee), Faculty Hospital Pilsen (approval number 239/2020). The committee also granted permission to access the raw data within the departmental medical database. All patients included in this study provided written informed consent for the procedure and for the future use of their perioperative and follow-up data.

\section{Competing interests}

The authors declare that they have no competing interests.

\section{Author details}

${ }^{1}$ Department of Obstetrics and Gynaecology, Faculty of Medicine and Dentistry, Palacky University and Faculty Hospital, Olomouc, Czech Republic. ${ }^{2}$ Biomedical Center, Faculty of Medicine in Pilsen, Charles University, Pilsen, Czech Republic. ${ }^{3}$ Department of Obstetrics and Gynecology, University Hospital, Pilsen, Czech Republic. ${ }^{4}$ Department of Gynecology and Obstetrics, Faculty of Medicine in Pilsen, Charles University, Pilsen, Czech Republic.

\section{Received: 10 June 2020 Accepted: 3 February 2021}

Published online: 17 February 2021

\section{References}

1. Swift S, Woodman P, O'Boyle A, Kahn M, Valley M, Bland D, et al. Pelvic Organ Support Study (POSST): the distribution, clinical definition, and epidemiologic condition of pelvic organ support defects. Am J Obstet Gynecol. 2005;192:795-806. https://doi.org/10.1016/j.ajog.2004.10.602.

2. Wu JM, Matthews CA, Conover MM, Pate V, Jonsson FM. Lifetime risk of stress urinary incontinence or pelvic organ prolapse surgery. Obstet
Gynecol. 2014;123:1201-6. https://doi.org/10.1097/AOG.0000000000 000286.

3. Obinata D, Yamaguchi K, Ito A, Murata Y, Ashikari D, Igarashi T, et al. Lower urinary tract symptoms in female patients with pelvic organ prolapse: efficacy of pelvic floor reconstruction. Int J Urol. 2014;21:301-7. https:// doi.org/10.1111/iju.12281.

4. Handa VL, Cundiff G, Chang HH, Helzlsouer KJ. Female sexual function and pelvic floor disorders. Obstet Gynecol. 2008;111:1045-52. https://doi. org/10.1097/AOG.0b013e31816bbe85.

5. Slieker-ten Hove MCP, Pool-Goudzwaard AL, Eijkemans MJC, SteegersTheunissen RPM, Burger CW, Vierhout ME. The prevalence of pelvic organ prolapse symptoms and signs and their relation with bladder and bowel disorders in a general female population. Int Urogynecol J. 2009;20:103745. https://doi.org/10.1007/s00192-009-0902-1.

6. Adjoussou SA, Bohoussou E, Bastide S, Letouzey V, Fatton B, de Tayrac R. Prévalence des troubles fonctionnels et associations anatomo-fonctionnelles chez les femmes présentant un prolapsus génital. Progrès en Urol. 2014;24:511-7. https://doi.org/10.1016/j.purol.2013.11.015.

7. Lucassen EA, la Chapelle CF, Krouwel E, Groeneveld M. Renal failure caused by severe pelvic organ prolapse. BMJ Case Rep. 2019;12:e229318. https://doi.org/10.1136/bcr-2019-229318.

8. Miyagi A, Inaguma Y, Tokoyoda T, Nakajima T, Sezaki R, Matsukawa T. A case of renal dysfunction caused by pelvic organ prolapse. CEN Case Rep. 2017:6:125-8. https://doi.org/10.1007/s13730-017-0257-2.

9. Wu JM, Vaughan CP, Goode PS, Redden DT, Burgio KL, Richter HE, et al. Prevalence and trends of symptomatic pelvic floor disorders in U. S. Women. Obstet Gynecol. 2014;123:141-8. https://doi.org/10.1097/ AOG.0000000000000057.

10. Martan A, Svabík K, Masata J, El-Haddad R, Pavlikova M. Correlation between stress urinary incontinence or urgency and anterior compartment defect before and after surgical treatment. Ces Gynekol. 2010;75:118-25.

11. Digesu GA, Chaliha C, Salvatore S, Hutchings A, Khullar V. The relationship of vaginal prolapse severity tosymptoms and quality of life. BJOG An Int J Obstet Gynaecol. 2005;112:971-6. https://doi.org/10.111 1/j.1471-0528.2005.00568.x.

12. Collins SA, O'Sullivan DM, Lasala CA. Correlation of POP-Q posterior compartment measures with defecatory dysfunction. Int Urogynecol J. 2012;23:743-7. https://doi.org/10.1007/s00192-011-1643-5.

13. Barber MD, Maher C. Apical prolapse. Int Urogynecol J. 2013;24:1815-33. https://doi.org/10.1007/s00192-013-2172-1.

14. Maher CM, Feiner B, Baessler K, Glazener CMA. Surgical management of pelvic organ prolapse in women: the updated summary version Cochrane review. Int Urogynecol J. 2011;22:1445-57. https://doi. org/10.1007/s00192-011-1542-9.

15. Davidson ERW, Casas-Puig V, Paraiso MFR, Ridgeway B, Ferrando CA. Pelvic organ prolapse recurrence and patient-centered outcomes following minimally invasive abdominal uterosacral ligament and mesh-augmented sacrohysteropexy. Female Pelvic Med Reconstr Surg. 2019. https ://doi.org/10.1097/SPV.0000000000000710.

16. Szymczak P, Grzybowska ME, Wydra DG. Comparison of laparoscopic techniques for apical organ prolapse repair-A systematic review of the literature. Neurourol Urodyn. 2019;38:2031-50. https://doi.org/10.1002/ nau.24115.

17. Committee Opinion No. 578. Obstet Gynecol. 2013;122:1134-8. https:// doi.org/10.1097/01.AOG.0000437384.88715.03.

18. Urdzík P, Kalis V, Blaganje M, Rusavy Z, Smazinka M, Havir M, et al. Pelvic organ prolapse and uterine preservation: a survey of female gynecologists (POP-UP survey). BMC Womens Health. 2020;20:241. https://doi. org/10.1186/s12905-020-01105-3.

19. Korbly NB, Kassis NC, Good MM, Richardson ML, Book NM, Yip S, et al. Patient preferences for uterine preservation and hysterectomy in women with pelvic organ prolapse. Am J Obstet Gynecol. 2013;209:470.e1-470.e6. https://doi.org/10.1016/j.ajog.2013.08.003.

20. Frick AC, Barber MD, Paraiso MFR, Ridgeway B, Jelovsek JE, Walters MD. Attitudes toward hysterectomy in women undergoing evaluation for uterovaginal prolapse. Female Pelvic Med Reconstr Surg. 2013;19:103-9. https://doi.org/10.1097/SPV.0b013e31827d8667.

21. Cardenas-Trowers O, Stewart JR, Meriwether KV, Francis SL, Gupta A Perioperative outcomes of minimally invasive sacrocolpopexy based on route of concurrent hysterectomy: a secondary analysis of the National 
Surgical Quality Improvement Program Database. J Minim Invasive Gynecol. 2020;27:953-8. https://doi.org/10.1016/j.jmig.2019.08.010

22. Davidson ERW, Thomas TN, Lampert EJ, Paraiso MFR, Ferrando CA. Route of hysterectomy during minimally invasive sacrocolpopexy does not affect postoperative outcomes. Int Urogynecol J. 2019;30:649-55. https:// doi.org/10.1007/s00192-018-3790-4

23. Gracia M, Perelló M, Bataller E, Espuña M, Parellada M, Genís D, et al. Comparison between laparoscopic sacral hysteropexy and subtotal hysterectomy plus cervicopexy in pelvic organ prolapse: a pilot study. Neurourol Urodyn. 2015;34:654-8. https://doi.org/10.1002/nau.22641.

24. Saliba E, Nisolle M, Tchente C, De Landsheere L. Doit-on réaliser systématiquement une hystérectomie subtotale dans le cadre d'une promontofixation cœelioscopique? Gynécologie Obs Fertil Sénologie. 2019;47:54954. https://doi.org/10.1016/j.gofs.2019.04.007.

25. Pan K, Cao L, Ryan NA, Wang Y, Xu H. Laparoscopic sacral hysteropexy versus laparoscopic sacrocolpopexy with hysterectomy for pelvic organ prolapse. Int Urogynecol J. 2016;27:93-101. https://doi.org/10.1007/ s00192-015-2775-9.

26. Illiano E, Giannitsas K, Costantini E. Comparison between laparoscopic sacrocolpopexy with hysterectomy and hysteropexy in advanced urogenital prolapse. Int Urogynecol J. 2020. https://doi.org/10.1007/s0019 2-020-04260-1.

27. Haylen BT, Maher CF, Barber MD, Camargo S, Dandolu V, Digesu A, et al. An International Urogynecological Association (IUGA)/International Continence Society (ICS) joint report on the terminology for female pelvic organ prolapse (POP). Int Urogynecol J. 2016;27:165-94. https:// doi.org/10.1007/s00192-015-2932-1.

28. Haylen BT, Maher CF, Barber MD, Camargo S, Dandolu V, Digesu A, et al. Erratum to: An International Urogynecological Association (IUGA)/International Continence Society (ICS) joint report on the terminology for female pelvic organ prolapse (POP). Int Urogynecol J. 2016:27:655-84. https://doi.org/10.1007/s00192-016-3003-y.

29. Krell RW, Girotti ME, Dimick JB. Extended length of stay after surgery. JAMA Surg. 2014;149:815. https://doi.org/10.1001/jamasurg.2014.629.

30. Barber MD, Kuchibhatla MN, Pieper CF, Bump RC. Psychometric evaluation of 2 comprehensive condition-specific quality of life instruments for women with pelvic floor disorders. Am J Obstet Gynecol. 2001;185:138895. https://doi.org/10.1067/mob.2001.118659.

31. Dindo D, Demartines N, Clavien P-A. Classification of surgical complications. Ann Surg. 2004;240:205-13. https://doi.org/10.1097/01.sla.00001 33083.54934.ae.
32. Smazinka M, Kalis V, Havir M, Havelkova L, Ismail KM, Rusavy Z. Obesity and its long-term impact on sacrocolpopexy key outcomes (OBELISK). Int Urogynecol J. 2019. https://doi.org/10.1007/s00192-019-04076-8.

33. Kalis V, Smazinka M, Rusavy Z, Blaganje M, Havir M, Havelkova L, et al. Laparoscopic sacrocolpopexy as the mainstay management for significant apical pelvic organ prolapse (LAP) study. Eur J Obstet Gynecol Reprod Biol. 2020;244:60-5. https://doi.org/10.1016/j.ejogrb.2019.10.049.

34. Srikrishna S, Robinson D, Cardozo L. Validation of the patient global impression of improvement (PGI-I) for urogenital prolapse. Int Urogynecol J. 2010;21:523-8. https://doi.org/10.1007/s00192-009-1069-5.

35. Haylen BT, Maher C, Deprest J. IUGA/ICS terminology and classification of complications of prosthesis and graft insertion-rereading will revalidate. Am J Obstet Gynecol. 2013;208:e15. https://doi.org/10.1016/j. ajog.2012.08.004.

36. Dietz HP, Haylen BT, Broome J. Ultrasound in the quantification of female pelvic organ prolapse. Ultrasound Obstet Gynecol. 2001;18:511-4. https ://doi.org/10.1046/j.0960-7692.2001.00494.x

37. Gutman RE, Rardin CR, Sokol ER, Matthews C, Park AJ, Iglesia CB, et al. Vaginal and laparoscopic mesh hysteropexy for uterovaginal prolapse: a parallel cohort study. Am J Obstet Gynecol. 2017;216:381.e1-38.e11.

38. Costantini E, Brubaker L, Cervigni M, Matthews CA, O'Reilly BA, Rizk D, et al. Sacrocolpopexy for pelvic organ prolapse: evidence-based review and recommendations. Eur J Obstet Gynecol Reprod Biol. 2016;205:60-5. https://doi.org/10.1016/j.ejogrb.2016.07.503.

39. Stepanian AA, Miklos JR, Moore RD, Mattox TF. Risk of Mesh extrusion and other mesh-related complications after laparoscopic sacral colpopexy with or without concurrent laparoscopic-assisted vaginal hysterectomy: experience of 402 patients. J Minim Invasive Gynecol. 2008;15:188-96. https://doi.org/10.1016/j.jmig.2007.11.006.

40. Tan-Kim J, Menefee SA, Luber KM, Nager CW, Lukacz ES. Prevalence and risk factors for mesh erosion after laparoscopic-assisted sacrocolpopexy. Int Urogynecol J. 2011;22:205-12. https://doi.org/10.1007/s0019 2-010-1265-3.

41. Kalis V, Rusavy Z, Ismail KM. Laparoscopic sacrohysteropexy: the Pilsner modification. Int Urogynecol J. 2020;31:1277-80. https://doi.org/10.1007/ s00192-019-04150-1.

\section{Publisher's Note}

Springer Nature remains neutral with regard to jurisdictional claims in published maps and institutional affiliations.
Ready to submit your research? Choose BMC and benefit from:

- fast, convenient online submission

- thorough peer review by experienced researchers in your field

- rapid publication on acceptance

- support for research data, including large and complex data types

- gold Open Access which fosters wider collaboration and increased citations

- maximum visibility for your research: over 100M website views per year

At BMC, research is always in progress.

Learn more biomedcentral.com/submissions 